\title{
Erratum to: On Definability in Dependence Logic
}

\author{
Juha Kontinen • Jouko Väänänen
}

Published online: 14 July 2010

(C) Springer Science+Business Media B.V. 2010

\section{Erratum to: J Log Lang Inf (2009) 18:317-332 DOI 10.1007/s10849-009-9082-0}

A correction is needed for the singular case $X=\varnothing$ in Theorems 4.9, 4.10, 5.1, and 5.2.

In Kontinen and Väänänen (2009), the open formulas of Dependence Logic $(\mathcal{D})$ were studied. Formulas of dependence logic express properties of sets of assignments (teams). It was shown in Väänänen (2007) that every formula of dependence logic can be represented in an equivalent form in existential second-order logic $\left(\Sigma_{1}^{1}\right)$ with an extra predicate, occurring only negatively, interpreting the team.

In Theorems 4.9 and 4.10 of Kontinen and Väänänen (2009) it was claimed that also the converse holds, i.e., that for every vocabulary $L$ and sentence $\phi \in \Sigma_{1}^{1}[L \cup$ $\{R\}$ ], in which $R$ is $k$-ary (for some $k \geq 1$ ) and occurs only negatively, there is a formula $\psi\left(y_{1}, \ldots, y_{k}\right) \in \mathcal{D}[L]$ such that for all models $\mathfrak{A}$ and teams $X$ with domain $\left\{y_{1}, \ldots, y_{k}\right\}$

$$
\mathfrak{A} \models_{X} \psi \Leftrightarrow(\mathfrak{A}, \operatorname{rel}(X)) \models \phi,
$$

The online version of the original article can be found under doi:10.1007/s10849-009-9082-0.

\section{J. Kontinen $(\varangle)$}

Department of Mathematics and Statistics, University of Helsinki,

P.O. Box 68, 00014 Helsinki, Finland

e-mail: juha.kontinen@helsinki.fi

J. Väänänen

ILLC, University of Amsterdam, Amsterdam, The Netherlands

J. Väänänen

Department of Mathematics and Statistics, University of Helsinki, Helsinki, Finland 
where $\operatorname{rel}(X)$ interprets $R$ and is defined as

$$
\operatorname{rel}(X)=\left\{\left(s\left(y_{1}\right), \ldots, s\left(y_{k}\right)\right): s \in X\right\} .
$$

This result does not however hold for $X=\emptyset$ due to the fact that for all models $\mathfrak{A}$ and formulas $\varphi$ of dependence logic, it holds that $\mathfrak{A} \models_{\varnothing} \varphi$ [See Lemma 3.9 in Väänänen (2007)]. It is now easy to find a sentence $\phi \in \Sigma_{1}^{1}[L \cup\{R\}]$ for which there is no formula $\psi\left(y_{1}, \ldots, y_{k}\right) \in \mathcal{D}[L]$ satisfying equation (1) for all $\mathfrak{A}$ and $X$. Let $\phi:=\perp$. Now $R$ appears only negatively in $\phi$, but if there were a formula $\psi$ satisfying (1), then any $L \cup\{R\}$-model of the form (A, Ø) should satisfy $\perp$, which is not the case.

The proofs of Theorems 4.9 and 4.10 are valid if the case $X=\emptyset$ is excluded. The following theorem now characterizes correctly the translation from the negative fragment of $\Sigma_{1}^{1}$ into dependence logic:

Theorem 0.1 Let $L$ be a vocabulary, and $R$ a $k$-ary predicate such that $R \notin L$. For every sentence $\phi \in \Sigma_{1}^{1}[L \cup\{R\}]$, in which $R$ occurs only negatively, there is a formula $\psi\left(y_{1}, \ldots, y_{k}\right) \in \mathcal{D}[L]$ such that for all models $\mathfrak{A}$ and teams $X$ with domain $\left\{y_{1}, \ldots, y_{k}\right\}$

$$
\mathfrak{A} \models X \quad \psi \Leftrightarrow(\mathfrak{A}, \operatorname{rel}(X)) \models \phi \vee \forall \bar{x} \neg R(\bar{x}) .
$$

Theorem 0.1 implies the correct formulations of Theorems 4.9 and 4.10, and, their IF logic analogues, Theorems 5.1 and 5.2: In Theorems 4.9 and 5.1, the correct assumption is that $Q$ is a downwards monotone class of $\{R\}$-models, which includes all structures of the form $(A, \emptyset)$. In Theorems 4.10 and 5.2, we have to add the assumption that $F \neq \emptyset$.

\section{References}

Kontinen, J., \& Väänänen, J. (2009). On definability in dependence logic. Journal of Logic, Language and Information, 18(3), 317-332.

Väänänen, J. (2007). Dependence logic, Vol. 70 of London mathematical society student texts. Cambridge: Cambridge University Press. 